\title{
Thermal Feedback for Simulated Lane Change Scenarios
}

\author{
Patrizia Di Campli San Vito, University of Glasgow, Glasgow, UK \\ Stephen Brewster, University of Glasgow, Glasgow, UK \\ Frank Pollick, University of Glasgow, Glasgow, UK \\ Stuart White, Jaguar Land Rover, Coventry, UK \\ Lee Skrypchuk, Jaguar Land Rover, Coventry, UK \\ iD https://orcid.org/0000-0002-9619-6161
}

Alexandros Mouzakitis, Jaguar Land Rover, Coventry, UK

\begin{abstract}
Most research into haptic feedback for in-car applications has used vibrotactile feedback. In this article, two simulator studies investigate novel thermal feedback during driving for a lane change task. The distraction and time differences of audio and thermal feedback were investigated in the first, with results showing that thermal feedback does not increase lane deviation, but the time to completed lane change is $1.82 \mathrm{~s}$ longer in the thermal than the audio condition. The second experiment explored the difference in variable changes of the thermal stimuli on the recognition rate and false positive recognition at the return to the neutral temperature. Variable alterations can have different effects on these tasks and are not mirrored for the directions of temperature change. This suggests that the design of thermal stimuli is highly dependent on what result should be maximized: recognition rate or minimal additional changes at the return to the neutral temperature.
\end{abstract}

\section{KEYWORDS}

Driving Simulator, Haptic, In-Car, Lane Change Task, Peltier, Speech, Tactile, Temperature, Thermal

\section{INTRODUCTION}

Driver distraction contributes highly to crashes and near crashes, mostly due to a secondary task or driving-related inattention (Klauer et al., 2006). The visual presentation of information on mobile devices and infotainment systems can add to the visual distraction. Finding alternative ways of providing information to drivers to increase attention on the driving task is therefore vital. Audio feedback, often as speech, is used as an alternative, but this can compete with conversations or music in the vehicle. Haptic feedback on the other hand can be presented unobtrusively to the driver without interrupting auditory tasks. When haptic feedback has been investigated for in-car applications, the focus was often on vibration. Tactile feedback has repeatedly reduced reaction times (Suzuki and Jansson, 2003; van Erp and van Veen, 2004), as well as lane deviation (Kern et al., 2009) and mental demand (van Erp and van Veen, 2004).

However, there are other aspects of cutaneous haptics which could potentially be used to convey information. Research into thermal feedback for mobile phones has shown that the direction of change (hot or cold) can be distinguished with $94 \%$ and the subjective intensity with $73 \%$ accuracy (Wilson et 
al., 2013). Subjective intensity was a combination of how fast and how much the temperature changed, representing the subjective levels moderate and strong. This suggests that thermal feedback could also be an effective way of conveying information to drivers. Additionally, thermal feedback can be unobtrusive (Lee and Lim, 2010). This is beneficial for feedback in a car, where sudden prompts can be distracting and therefore dangerous. Thermal cues can elicit affective responses in different contexts (Salminen et al., 2011; Wilson et al., 2017) presenting interesting and novel possibilities for in-vehicle interaction.

This article provides a more detailed analysis of the two experiments reported in Di Campli San Vito et al. (2018), capturing some basic data of the effects of thermal feedback during driving. The studies employed a simulated lane change task, where the direction of lane change in the thermal condition was given by the direction of temperature change (warm or cool). These investigations can be used as a baseline for future research into thermal in-car applications. The impact of thermal feedback on the driving performance was investigated and it was found that in the thermal condition the completion of a lane change was 1.82s slower than in the speech baseline. Furthermore, modulations of several stimuli parameters of the thermal feedback were explored. The earlier analysis did not investigate potential differences in thermal perception based on gender nor did they discuss user comments and feedback. These aspects will be illuminated in the present paper.

\section{BACKGROUND}

Haptic feedback has been the focus of research for some time. Mostly, vibration, or vibrotactile feedback, has been investigated for several applications (Brewster and Brown, 2004; Brown et al., 2006). Among those are the presentation of warnings (Brown and Kaaresoja, 2006) and instructions (Pielot et al., 2010).

In cars, haptic feedback is often used for navigation. Kern et al. (2009) attached vibrotactile actuators to the steering wheel and used vibration in combination with auditory and visual cues to convey navigation information for lane changes. In their experiments, they encountered problems when presenting vibration alone on one side of the steering wheel: participants had trouble identifying the vibrating side. Additionally, the information presented was not easily distinguished when presented by itself and influenced the driving performance negatively. When vibration was presented in a multimodal setting, with visual and auditory cues, driving performance was increased and participants preferred the visual and tactile combination.

Circumventing the identification issues of vibration on the steering wheel, Medeiros-Ward et al. (2010) used shear feedback to convey navigational information. The feedback device was also mounted on the steering wheel, with participants touching it with the tip of their index fingers. The skin of the finger was then pushed towards the turning direction. They compared this feedback to audio navigation and found that they were equivalent when participants were driving without any additional tasks present, but while the performance with audio feedback decreased with a phone call as secondary task, shear feedback was not influenced. This suggests that tactile feedback could be less susceptible to distractions by secondary auditory tasks, such as radio programmes or phone calls.

Moving away from the steering wheel, van Erp and van Veen (2004) presented navigational cues under the thigh by embedding vibrotactile actuators into the seat. The vibrating side indicated the turning direction. Additionally, different vibration patterns encoded the distance from the turning point. In the bimodal presentation of visual and tactile feedback they found a significant reduction of reaction time. Furthermore, the workload was significantly higher in the visual-only condition. Under different workload conditions they measured the peripheral detection time of randomly presented visual cues and observed a $10 \%$ increase in the visual condition.

This research shows that tactile feedback and multimodal combinations of it can successfully be used for in-car applications. 


\section{Thermal Interaction}

As modern cars already use heated steering wheels and seats, drivers are familiar with thermal changes in the car. The concept of using temperature changes as means for feedback has been mostly investigated for mobile devices. Recommendations for its use have been provided by Wilson et al. (2011). They identified the thenar region (base of the thumb) as most suited for thermal feedback. In their study, they compared several rates of temperature change and identified $1{ }^{\circ} \mathrm{C} / \mathrm{s}$ and $3{ }^{\circ} \mathrm{C} / \mathrm{s}$ as equally effective. While the slower rate took longer to be identified, it was rated as more comfortable. Thermal icons were investigated in another suite of experiments (Wilson et al., 2013). Four icons differing in direction of temperature change (warm/cold), rate of change $\left(1^{\circ} \mathrm{C} / \mathrm{s}\right.$ and $\left.3^{\circ} \mathrm{C} / \mathrm{s}\right)$ and extent of change $\left(3^{\circ} \mathrm{C}\right.$ and $\left.6^{\circ} \mathrm{C}\right)$ were tested in an outdoor task. While the complete icons were only correctly detected with a recognition rate of $64 \%$, the individual parameters direction and rate of change were recognized with $94 \%$ and $73 \%$, respectively.

These findings were adapted to explore the interpretation of thermal feedback in the context of several different situations (Wilson et al, 2015). Participants described the meaning of thermal feedback for use cases such as restaurant rating and social media usage. Warmer temperatures were consistently connected to more positive attributes like physical presence and recent activity. Cooler temperatures represented less active and less positive meanings. If these kinds of interpretations turned out to be consistent in an in-car environment, thermal feedback could potentially be effective even without extensive training.

One of the possible use cases relevant to driving is navigation. Thermal feedback has already been investigated for navigation purposes, both for pedestrians and a 2D maze. Wettach et al. (2007) devised a mobile thermal device that helped pedestrians find their destination by warming the device when the correct direction was targeted. Five different temperatures were implemented, and the participants completed extensive training before the trial. Even though participants were able to find their destination, they commented on missing a sense of distance when using the device. Tewell et al. (2017) assisted navigation through a 2D maze by presenting continuous thermal feedback. The device was warm when the correct path through the maze was taken and turned cooler when it was left. The use of thermal feedback reduced the number of moves needed to finish the maze, but increased the time needed to solve the puzzle. The navigation was improved by applying thermal feedback, which could be as useful when providing turn-by-turn navigation cues in cars.

\section{User Experiments}

Two experiments were conducted to investigate the suitability of thermal feedback during driving. Navigational cues were presented thermally for a lane change task. One thermoelectric device was presented on the surface next to the participants and they were asked to touch it with the index finger of their right hand, while driving one-handed with the left. When the device cooled, participants should change to the left and when it warmed to the right lane. The apparatus used in both experiments was the same and will be described before the details of the experiment designs are provided.

\section{Apparatus}

The simulator environment was implemented in OpenDS, depicting a five-lane motorway. It was shown on a 23.6-inch HannsG HL249 screen, which was connected to a DELL XPS 159550 laptop operating Windows 10. The steering wheel attached was a Logitech G920 Driving Force wheel and Sennheiser HD 25-1 II Basic Edition headphones were used throughout the experiments, playing car noises and audio feedback, if applicable. The thermoelectric device was a $2 \times 2 \mathrm{~cm}$ Peltier, firmly attached to a heatsink, operated via Bluetooth and built by SAMH Engineering, see Figure 1 (left). The car had a constant speed of $100 \mathrm{~km} / \mathrm{h}$, participants had no influence on the speed of the car. The setup can be seen in Figure 1 (right). The Ethics Committee of the University of Glasgow approved both study designs. 


\section{Study One: User Distraction and Comparison With Speech Instructions}

This first study had several goals:

- Comparing driving data during the presentation of thermal feedback and speech to assess the level of distraction;

- Gathering user feedback on the experience and preference of both techniques and comparing the reported workload;

- Examining the delay of thermal feedback detection.

As mentioned by Kern et al. (2009), new feedback types tend to be more distracting than established ones and auditory feedback is well-known in cars. The distraction level posed by thermal feedback was therefore expected to be higher, influencing the driving performance, measured in this study through lane deviation. The presented thermal feedback was slowly increasing, raising the expectation that this feedback would be experienced and rated as less disruptive and more pleasant than sudden speech instructions. Geitner et al. (2015) observed that the sensitivity to vibration presented on an accelerator pedal can be influenced by gender, with female participants showing more sensibility. Additionally, a literature review by Karjalainen (2012) on the influence of gender on thermal comfort showed that females are more sensitive to deviation from neutral temperatures and express their discomfort more clearly. Therefore, the results of this study were evaluated for the whole group of participants as well as for the genders female and male separately, to examine if gender influenced perception and preference. All participants self-reported their gender as being one of the two, the additional option other was given, but not chosen. Additionally, prior research used warm temperatures to represent the destination in their navigation tasks. To confirm the suitability of the mapping warm to destination, participants were posed an indirect question to capture their preference.

\section{Study Design}

The study was a within-subjects design with one independent variable: feedback type (thermal/ audio). The experiment itself was separated into two parts: in each part participants were presented with one block of 10 thermal and one block of 10 auditory cues. The order of the feedback types for both parts was counterbalanced by iterating through all possible permutations of the two feedback types within the two parts.

Figure 1. Peltier device and experiment setup

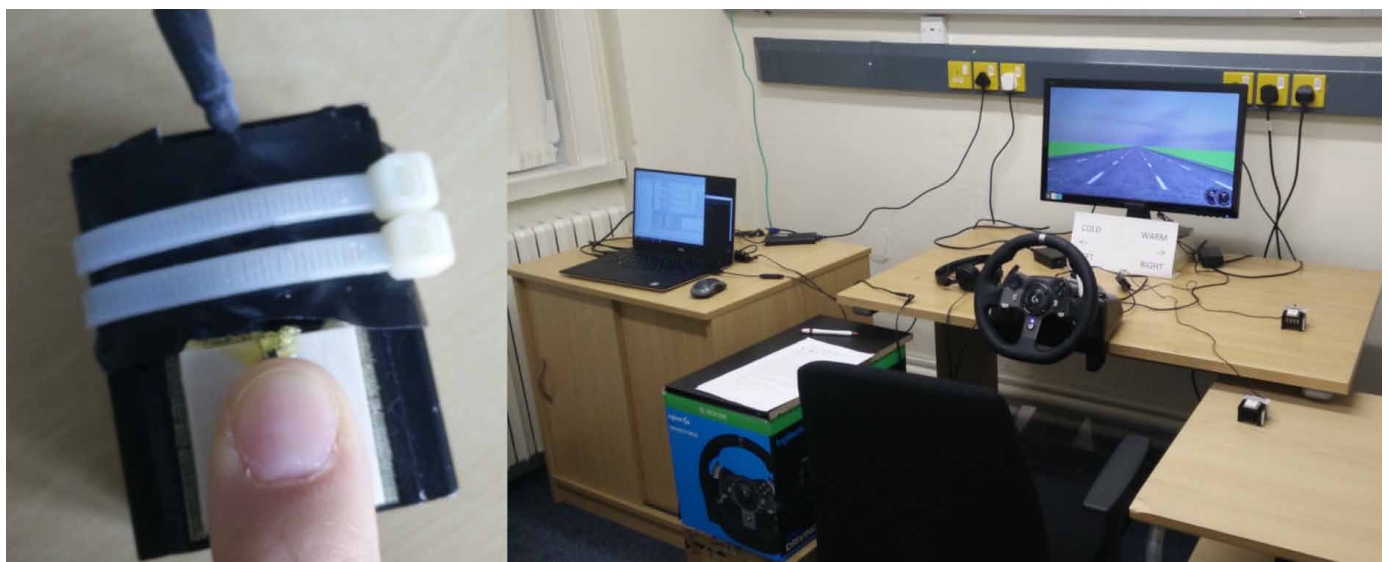


Figure 2. Thermal Stimuli for the first experiment

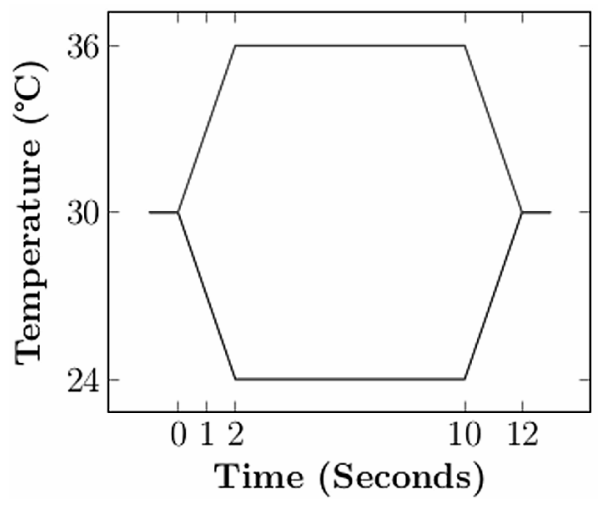

In the thermal condition the direction of temperature change indicated the direction of lane change: when the device turned warm, participants should change a lane to the right, if it turned cool, a lane to the left. The temperatures were chosen in accordance with Wilson et al. $(2013,2011)$. The neutral temperature was set to $30^{\circ} \mathrm{C}$, from which the device heated up to $36^{\circ} \mathrm{C}$ or cooled to $24^{\circ} \mathrm{C}$. This temperature was reached with a rate of $3^{\circ} \mathrm{C} / \mathrm{s}$, resulting in a total of $2 \mathrm{~s}$ of temperature change. After this, the warm or cool temperature was kept constant for $8 \mathrm{~s}$ and then returned to the neutral temperature with the same rate of change. The temperature change starting from the neutral temperature until it returned to neutral was introduced to the participants as one cue, see Figure 2.

In the first part of the experiment, the virtual car should be kept within the middle lane, without any actual lane change occurring. Participants were asked to report the changes they felt or commands they heard. The lane deviation was calculated for the driving data gathered in this first part of the experiment, to investigate if the presentation of the stimuli alone influenced the driving performance and posed a distraction. To increase the comparability of the two feedback types, two different sets of audio cues were used: a male synthesized voice uttered warm and cold in the first part of the experiment, and then right or left in the second. The commands right or left would be more likely to elicit a response than temperature change as a new, unassociated feedback, and therefore influence the lane deviation.

Lane deviation was observed for four different stages: the $5 \mathrm{~s}$ before the onset of the stimulus (as baseline), during the $2 \mathrm{~s}$ of thermal change, the $8 \mathrm{~s}$ of constant temperature and the $2 \mathrm{~s}$ of the return to the neutral temperature. These time frames were chosen to allow a more detailed observation of the driver distraction at different stages of the thermal feedback. The deviation was calculated as the Root Mean Square Error (RMSE) of the distance from the center of the car to the center of the lane.

In the second part of the study, the participant's task was to change lanes, when they felt or heard instructions. The time to complete a lane change and the number of correct lane changes were collected in this part. The time to complete lane change was calculated from the onset of the stimulus to the moment when the car had fully entered the target lane. Participants filled in NASA TLX (Hart \& Staveland, 1988) questionnaires (on a 10-point Likert scale) after both conditions to report workload, as well as four additional subjective ratings (on a 5-point Likert scale) on how pleasant, comfortable, disruptive and complicated the feedback was.

At the end of the experiment, participants were asked to rate how familiar they were with driving simulators, audio feedback and thermal feedback prior to the experiment on a 5-point Likert scale (1 equaled no experience). Racing games were counted towards experience with driving simulators. 


\section{Participants}

Fourteen participants completed the study, all right-handed and without reported sensory impairments in their hands. They had at least corrected vision and held a valid driving license. More details on the participant population and their experience with the technologies prior to the experiment can be found in Table 1.

\section{Procedure}

Participants were presented with an information sheet and asked to sign a consent form. Afterwards they were given some time to get used to the driving simulator, where they could drive on the motorway until they felt comfortable with the procedure. Afterwards participants started the first part of the experiment, either starting with the audio or the thermal condition. Before the thermal condition, the cues were introduced to the participants, presenting each temperature change, including the return to the neutral $30^{\circ} \mathrm{C}$. There was a short break between the two conditions.

After each condition in the second part of the experiment, the participants filled in the NASA TLX questionnaire and the additional questions on the subjective rating. The preference of the turning direction was posed as follows: Imagine you were presented with thermal feedback on the steering wheel for navigation purposes, where the devices of one side of the wheel will be warmed, while the other side will be cooled, how would you interact: If the right side of the steering wheel was warmed, while the left side was cooled, I would turn to the: left / right. Additionally, participants were specifically asked for suggestions concerning use cases and locations in the car for thermal feedback. The study took about one hour, and participants were compensated with $£ 6$.

\section{Results}

The data between the different conditions was compared using paired t-tests, if the data was normally distributed, and paired Wilcoxon tests otherwise. The comparison between the genders was done using the unpaired version of the same.

\section{Lane Deviation}

The RMSE of the lane deviation ranged between $33 \mathrm{~cm}$ and $35 \mathrm{~cm}$ in the audio and $37 \mathrm{~cm}$ and $42 \mathrm{~cm}$ in the thermal condition. Overall, the lane deviation in the thermal condition was between $3.7 \mathrm{~cm}$ and $7.2 \mathrm{~cm}$ higher, but those differences turned out to not be significant, and a comparison between genders showed no significant difference either. The results of the tests are shown in Table 2.

Table 1. Participant data of Study 1 for all participants together and gender separately

\begin{tabular}{|c|c|c|c|c|c|c|}
\hline & $\begin{array}{l}\text { Number of } \\
\text { Participants }\end{array}$ & $\begin{array}{c}\text { Age } \\
\text { (Years) }\end{array}$ & $\begin{array}{c}\text { Driving } \\
\text { Experience } \\
\text { (Years) }\end{array}$ & $\begin{array}{l}\text { Experience } \\
\text { Simulator }\end{array}$ & $\begin{array}{c}\text { Experience } \\
\text { Audio }\end{array}$ & $\begin{array}{c}\text { Experience } \\
\text { Thermal }\end{array}$ \\
\hline All & 14 & $\begin{array}{l}20-32 \\
(M=26.36 \\
\mathrm{SD}=4.68)\end{array}$ & $\begin{array}{l}1-17 \\
(M=7.71 \\
S D=4.92)\end{array}$ & $\begin{array}{l}1-5 \\
(M=2.00 \\
S D=1.29)\end{array}$ & $\begin{array}{l}1-5 \\
(M=2.93 \\
S D=1.63)\end{array}$ & $\begin{array}{l}1-3 \\
(M=1.18 \\
S D=0.54)\end{array}$ \\
\hline Female & 8 & $\begin{array}{l}20-32 \\
(M=24.75 \\
S D=4.77)\end{array}$ & $\begin{array}{l}1-17 \\
(M=6.88 \\
S D=6.03)\end{array}$ & $\begin{array}{l}1-4 \\
(M=1.75 \\
S D=1.16)\end{array}$ & $\begin{array}{l}1-5 \\
(M=2.75 \\
S D=.75)\end{array}$ & $\begin{array}{l}1 \\
(M=1.00 \\
S D=0.00)\end{array}$ \\
\hline Male & 6 & $\begin{array}{l}23-34 \\
(M=28.50 \\
S D=3.94)\end{array}$ & $\begin{array}{l}5-14 \\
(M=8.83 \\
S D=3.06)\end{array}$ & $\begin{array}{l}1-5 \\
(M=2.33 \\
S D=1.47)\end{array}$ & $\begin{array}{l}1-5 \\
(M=3.17 \\
S D=1.57)\end{array}$ & $\begin{array}{l}1-3 \\
(M=1.42 ; \\
S D=0.80)\end{array}$ \\
\hline
\end{tabular}




\section{Time to Complete a Lane Change}

$4368.1 \mathrm{~ms}$ were on average needed to complete a lane change. This was higher for thermal $(M=$ $5.28 \mathrm{~s}, S D=0.75)$ than audio $(M=3.46 \mathrm{~s}, S D=0.42)$, with a difference of $1.82 \mathrm{~s}$ (see Figure 3$)$. This difference was statistically significant for all participants $(\mathrm{t}(13)=12.82, \mathrm{p}<0.001)$, and for both genders (female: $\mathrm{t}(7)=8.34, \mathrm{p}<0.001$; male: $\mathrm{t}(5)=11, \mathrm{p}<0.001$ ). Women changed $1.68 \mathrm{~s}$ faster in the audio condition, men 2.02s. There was also a significant difference between the genders, for both conditions (thermal: $\mathrm{t}(11)=5.9, \mathrm{p}<0.001$; audio: $\mathrm{t}(7)=21.67, \mathrm{p}<0.001$ ). Females changed $0.21 \mathrm{~s}$ faster in the thermal condition than men, while men turned $0.1 \mathrm{~s}$ faster in the audio condition than women.

\section{Stimulus Recognition}

Recognition accuracy of the feedback in the first part of the study was $100 \%$ for audio and $97 \%$ for thermal; 4 out of 140 thermal cues were incorrectly recognised. Three of these were missed and in one case the temperature direction was identified wrongly. However, 25 additional stimuli were identified. These were mostly misinterpretations of the temperature change back to neutral: participants mistook the change back to neutral as a new stimulus, a false positive.

In the second part, all audio stimuli were recognized correctly. The recognition error rate of thermal feedback was $11 \%$ (16 missed stimuli). The number of false positive stimuli went down to a total of 8 , for changes back to the neutral condition both from cold (6 times) and warm (2). Interestingly, all of these occurred within the female participant population. Apart from this, there were no significant differences for recognition between genders in either part of the experiment.

Table 2. Results of the statistical tests for the Lane Deviation of the first part of the experiment

\begin{tabular}{|l|l|l|l|l|}
\hline & \multicolumn{1}{|c|}{ Before } & \multicolumn{1}{c|}{ During } & \multicolumn{1}{c|}{ Constant } & \multicolumn{1}{c|}{ Return } \\
\hline Condition & $\begin{array}{l}\mathrm{V}=29 \\
\mathrm{p}=0.15\end{array}$ & $\begin{array}{l}\mathrm{t}(13)=1.11 \\
\mathrm{p}=0.29\end{array}$ & $\begin{array}{l}\mathrm{t}(13)=1.39 \\
\mathrm{p}=0.19\end{array}$ & $\begin{array}{l}\mathrm{t}(13)=1.02 \\
\mathrm{p}=0.33\end{array}$ \\
\hline Gender Thermal & $\begin{array}{l}\mathrm{t}(8.12)=0.42 \\
\mathrm{p}=0.69\end{array}$ & $\begin{array}{l}\mathrm{t}(9.19)=0.19 \\
\mathrm{p}=0.85\end{array}$ & $\begin{array}{l}\mathrm{t}(5.91)=0.64 \\
\mathrm{p}=0.55\end{array}$ & $\begin{array}{l}\mathrm{t}(7.72)=0.73 \\
\mathrm{p}=0.49\end{array}$ \\
\hline Gender Audio & $\begin{array}{l}\mathrm{t}(9.73)=0.31 \\
\mathrm{p}=0.76\end{array}$ & $\begin{array}{l}\mathrm{t}(10.07)=0.47 \\
\mathrm{p}=0.65\end{array}$ & $\begin{array}{l}\mathrm{t}(6.84)=0.01 \\
\mathrm{p}=0.99\end{array}$ & $\begin{array}{l}\mathrm{V}=21 \\
\mathrm{p}=0.76\end{array}$ \\
\hline
\end{tabular}

Figure 3. Time to finished Lane Change for all participants and genders, error bars always show the standard error

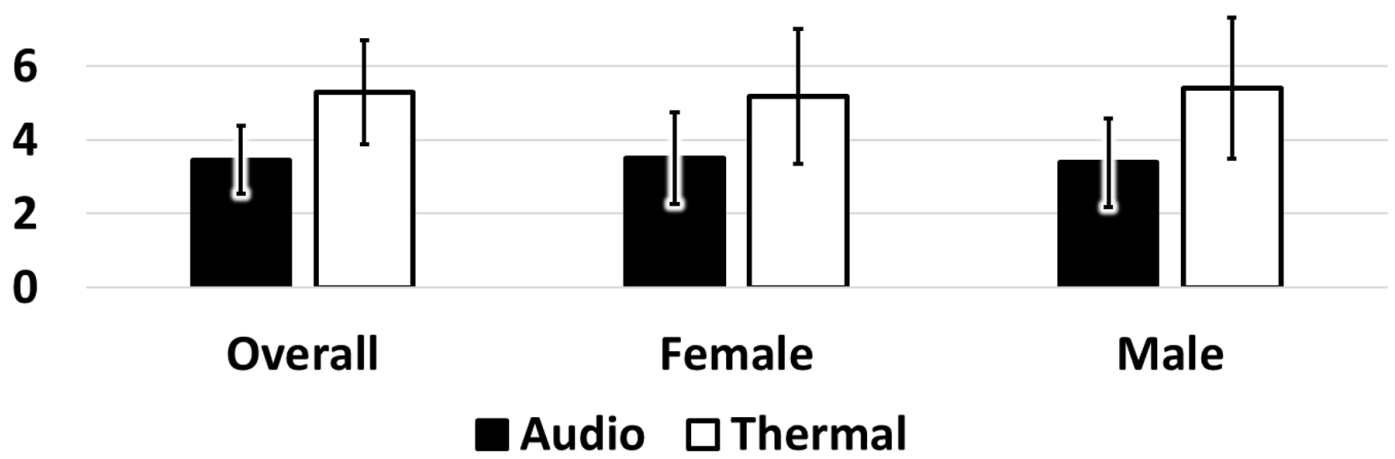




\section{Subjective Rating}

Figure 4 shows the results of the NASA TLX questionnaire. The factors Mental Demand $(\mathrm{t}(13)=$ $3.59, \mathrm{p}=0.003$; median (audio $)=3.00$, median $($ thermal $)=7.00)$, Performance $(\mathrm{V}=8.5, \mathrm{p}=0.02$; median $($ audio $)=8.00$, median $($ thermal $)=5.00)$ and Frustration $(\mathrm{V}=7.5, \mathrm{p}=0.03$; median $($ audio $)=$ 1.25 , median (thermal $)=3.75$ ) were significantly different between the conditions for all participants. The evaluation of the gender specific data showed no significant differences for any of the factors for the female participant population, while Mental Demand was significantly higher in the thermal condition for men $(\mathrm{t}(5)=3.14, \mathrm{p}=0.03$; median (audio) $=3$, median(thermal) $=6.75$ ). The comparison of the workload data between genders showed a significant difference for the factor Physical Demand in the thermal condition $(\mathrm{V}=40, \mathrm{p}=0.04$; $\operatorname{median}($ female $)=2.25$, median $($ male $)=4.75$ ).

Results of the additional subjective ratings can be seen in Figure 5. The only significant difference between conditions for all participants was found for the parameter complexity $(V=0, p=0.00$; median $($ audio $)=1$, median $($ thermal $)=3.00$ ). This was mirrored within both genders (female: $\mathrm{V}=0$, $\mathrm{p}=0.04$; median $($ audio $)=1.25$, median $($ thermal $)=2.25 /$ male: $\mathrm{V}=0, \mathrm{p}=0.04$; median (audio) $=1.00$, median (thermal) $=3.50$ ). When comparing the genders to each other, there was a significant difference for disruptiveness in the audio condition $(\mathrm{V}=8.5, \mathrm{p}=0.04$; median $($ female $)=1.00$, median $($ male $)=2.25)$.

Figure 4. Results of NASA TLX questionnaire for all participants and genders. Significant results between modalities are marked with asterisk $(*)$, between genders with a tilde $(\sim)$ and between modalities within gender groups with plus $(+)$ for male and minus (-) for female participant groups

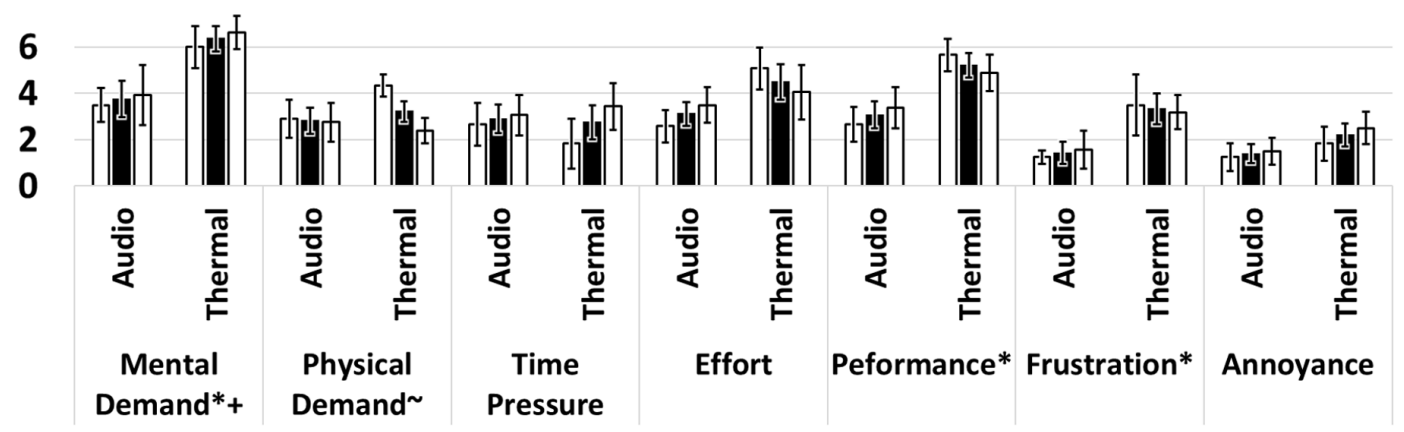

$\square$ male $\square$ all $\square$ female

Figure 5. Results of the additional subjective questions for all participants and genders

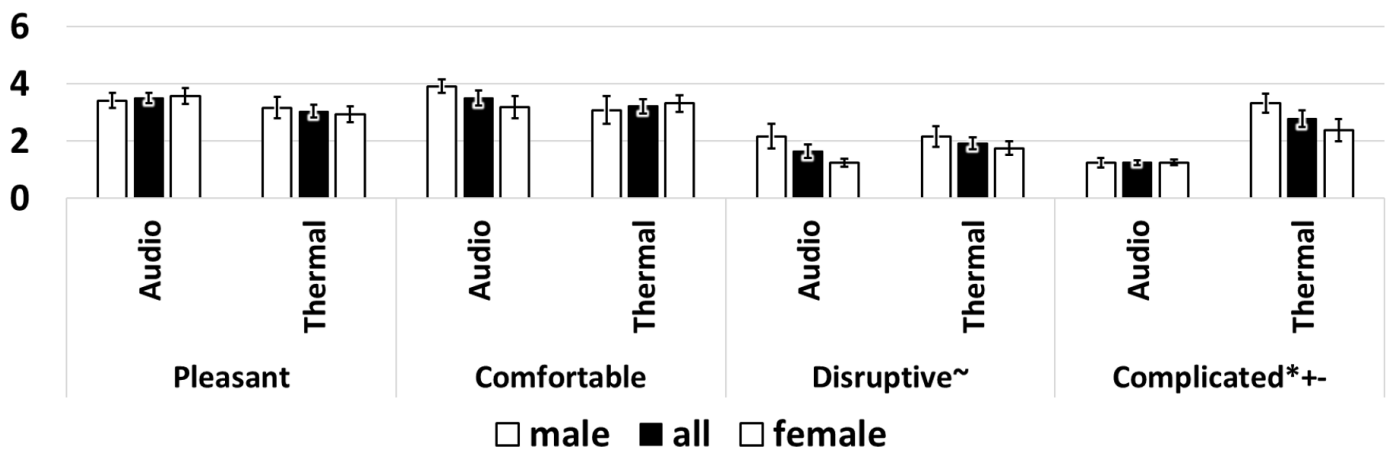




\section{Turning Direction}

When asked for their preference regarding the mapping of turning direction to temperature, 13 participants chose "right", which corresponded to the warm side, while only one of the women chose "left", the cold side.

\section{Suggested Locations and Applications}

Participants were asked to name locations and applications for thermal feedback in the car. While most participants suggested as location the steering wheel (9), others also mentioned the gear stick (5), seat (4) as well as belt and gear pedals (each 1). Some example applications were directed at specific locations, such as Full wheel going warm [...] would mean danger is approaching (P10), Speeding - when over the speed limit the wheel heats up (P03) or gearstick - indicate up or down a gear (P13). The idea of warning of approaching danger was shared by several participants, even though they named different kinds of danger: another car has entered a blind spot (P12), forget to turn on light at night (P11), danger of crash (P05), weather conditions (P09, P14) and How far away you were from hazards (P14). P02 and P07 mentioned the use of thermal feedback for parking. P14 suggested using thermal feedback for navigation: plan routes, avoid traffic.

\section{Discussion}

This first study was conducted to explore thermal feedback during driving, compare some features to audio feedback and investigate the impact of gender on the results. There was no significant difference in lane deviation. The deviation was a bit smaller for audio, however, so a more pronounced difference might be observable with a bigger sample size.

Lane changes consistently took longer when the change was initiated by thermal feedback: an average of $1.82 \mathrm{~s}$ longer over all participants, where women changed $1.68 \mathrm{~s}$ and men $2.02 \mathrm{~s}$ faster in the audio condition. Comparison between genders showed significant differences as well, with women being faster in the thermal condition than men and men faster than women in the audio condition. These results could have several reasons, one of them being that female participants might have been faster in the detection of the stimuli. Additional experiments should investigate the detection time of thermal feedback in more detail.

Stimuli detection was perfect for speech, while thermal feedback had a recognition rate of $97 \%$ in the first part of the experiment and $89 \%$ in the second. Some participants had problems understanding if the temperature change back to neutral was a new stimulus or not. This suggests that a different stimulus representation with less extent of change or less distinguishable transition to the neutral temperature should be investigated. A reduction in stimulus length could also change the perception, as the skin might be less adapted to the stimulus temperature when it is returned to the neutral temperature. While gender does not seem to have any influence on the recognition rate, the investigation of the false positive returns during the second part of the experiment showed that all 8 additional changes were done by female participants. The number of false positive recognitions in the first part of the experiment, however, was not significantly different between genders.

Thermal feedback was rated as more complex and the mental demand and frustration described by the participants were higher. Audio feedback was named as being more familiar and therefore easier to utilize, which was given as a reason for rating the thermal feedback more negatively. Furthermore, an additional level of mapping was needed in the thermal condition: warm had to be translated to right. Overall, participants reported that they sometimes had difficulties distinguishing between warm and cold at first. It took them some time to be sure about the temperature direction, which might have added to the preference of speech.

Some interesting results were found when looking into the rating separately for each gender. While workload parameters showed no significant difference for women, men rated the Mental Demand posed by thermal feedback as higher. Furthermore, the comparison of the workload of both genders with each other showed a significant difference in Physical Demand in the thermal condition: men 
rated it significantly higher than women. These results would suggest that men seem to experience thermal feedback as more demanding than women. Another difference between the genders occurred when the male participant pool rated audio feedback as significantly more disruptive than the female counterparts.

The mapping of warmth to destination temperature was confirmed by participants, as almost all of them chose the same answer. But when asked for applications in the car, only one participant suggested navigation. Most participants envisioned thermal feedback for warnings. However, the results imply that thermal feedback should be used for applications that are not time urgent, because it needs some time to be recognized.

A second experiment was designed and conducted to investigate several stimuli designs, varying the factors discussed as possibly having an influence on the false positive recognitions.

\section{Study Two: Investigation of Different Stimuli Designs}

This study was designed to evaluate the impact of different design decisions on recognition rate and false positive recognition at the return to neutral temperature. Apart from the direction of change (warm/ cold), again indicating the direction of lane change, three more parameters were varied and tested.

\section{Study Design}

The experiment was conducted as within-subjects study and had 4 independent variables:

- $\quad$ Direction of temperature change (DIR): Warm or Cold

- Length of stimuli presentation (LEN): $0 \mathrm{~s}, 3 \mathrm{~s}$ or $6 \mathrm{~s}$

- Extent of temperature change (EXT): $3^{\circ} \mathrm{C}$ or $6^{\circ} \mathrm{C}$

- Rate of change at the return to the neutral temperature (ROC): Slow rate of $1^{\circ} \mathrm{C} / \mathrm{s}$ or angled rate of $0.5 \mathrm{C} \% \mathrm{~s}$

Figure 6 depicts the temperature changes of all evaluated stimuli. The rate of change was influenced by restrictions of the hardware used for the experiment: only changes of either $3 \mathrm{C} / \mathrm{s}$ or $1^{\circ} \mathrm{C} / \mathrm{s}$ were possible. The angled rate of $0.5^{\circ} \mathrm{C} / \mathrm{s}$ was simulated by changing the temperature with $1{ }^{\circ} \mathrm{C} / \mathrm{s}$ and then keeping that temperature for 1s, before changing again (compare dashed lines in Figure 6).

Participants were again instructed to change a lane to the left when they felt a cold temperature change and to the right if it was warm. The warm and cold stimuli were evaluated separately in analysis, as differences in perception between the two have been pointed out by Wilson et al. (2011).

\section{Figure 6. Thermal Stimuli of the second experiment}

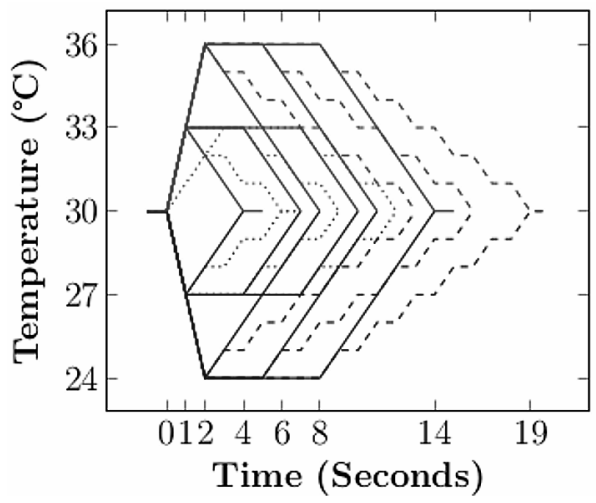


A convention for labelling the stimuli was introduced with a listing of the value of the four parameters (DIR-LEN-EXT-ROC). For example: a warm temperature change of $6^{\circ} \mathrm{C}$ with a return rate of $1^{\circ} \mathrm{C} / \mathrm{s}$ and a presentation length of 0 s (returning to neutral right after reaching the destination temperature) was labelled w-0-6-s.

All 24 combinations of these parameters were presented to each participant 3 times, resulting in 72 stimuli. The order of the cues was randomized.

\section{Participants}

All participants possessed a valid driving license and reported no sensory impairments on their hands. They were all right-handed and had at least corrected vision. Additional information on participants of the second study are presented in Table 3, including how familiar they were with driving simulators and thermal feedback prior to the experiment.

\section{Procedure}

After reading the information sheet and signing the consent form, participants were given time to get used to the driving simulator. Afterwards, they were introduced to the different thermal cues. The experiment task then consisted of 8 blocks with 9 stimuli each, separated by small breaks. Demographic data was collected at the end and participants were paid $£ 6$ for completing this one-hour study.

\section{Results}

\section{Lane Changes at the Return to Neutral Temperature}

The number of additional lane changes for return to the neutral temperature for warm and cold temperatures was evaluated with a repeated measures ANOVA each, with predictor variables LEN, EXT and ROC as within factors and gender as between subject factor. Results showed no significant main effects or interactions, see Table 4. For warm stimuli the parameter LEN violated sphericity and was corrected with Greenhouse-Geisser. Figure 7 shows the rate of the false positive changes ordered by parameters; Figure 8 shows them for each stimulus.

Even though there were no statistically significant results, some trends could be seen. LEN of 6 seconds led to more lane changes for both warm and cold stimuli. Additionally, EXT seemed to impact the changes in opposite ways: while a higher extent increased lane changes for warm temperatures, it seemed to reduce it for cold temperatures. ROC only seemed to have a small impact on cold stimuli, not warm. A more extensive study must be conducted to see if these trends influence the results consistently.

Table 3. Participant data of Study 2 for all participants together, and gender separately

\begin{tabular}{|c|c|c|c|c|c|}
\hline & $\begin{array}{l}\text { Number of } \\
\text { Participants }\end{array}$ & $\begin{array}{c}\text { Age } \\
\text { (Years) }\end{array}$ & $\begin{array}{c}\text { Driving } \\
\text { Experience } \\
\text { (Years) }\end{array}$ & $\begin{array}{l}\text { Experience } \\
\text { Simulator }\end{array}$ & $\begin{array}{c}\text { Experience } \\
\text { Thermal }\end{array}$ \\
\hline All & 16 & $\begin{array}{l}19-35 \\
(M=25.88 \\
S D=5.06)\end{array}$ & $\begin{array}{l}0-17 \\
(M=75.28 \\
S D=5.20)\end{array}$ & $\begin{array}{l}1-5 \\
(M=3.25 \\
S D=1.29)\end{array}$ & $\begin{array}{l}1-4 \\
(M=2.00 \\
S D=1.32)\end{array}$ \\
\hline Female & 8 & $\begin{array}{l}19-35 \\
(M=24.75 \\
S D=5.63)\end{array}$ & $\begin{array}{l}1-17 \\
(M=6.13 \\
S D=6.17)\end{array}$ & $\begin{array}{l}1-5 \\
(M=3.00 \\
S D=1.31)\end{array}$ & $\begin{array}{l}2 \\
(M=2.00 \\
S D=1.31)\end{array}$ \\
\hline Male & 8 & $\begin{array}{l}21-35 \\
(M=27.00 \\
S D=4.50)\end{array}$ & $\begin{array}{l}0-14 \\
(M=4.44 \\
S D=4.27)\end{array}$ & $\begin{array}{l}1-5 \\
(M=3.55 \\
S D=1.31)\end{array}$ & $\begin{array}{l}1-4 \\
(M=2.00 \\
S D=1.41)\end{array}$ \\
\hline
\end{tabular}


Table 4. Test results for the ANOVA tests for the number of Lane Changes at the return to neutral

\begin{tabular}{|c|c|c|c|c|c|c|c|}
\hline & LEN & EXT & ROC & $\begin{array}{l}\text { LEN* } \\
\text { EXT }\end{array}$ & $\begin{array}{l}\text { LEN* } \\
\text { ROC }\end{array}$ & $\begin{array}{l}\text { EXT* } \\
\text { ROC }\end{array}$ & $\begin{array}{l}\text { LEN* } \\
\text { EXT* } \\
\text { ROC }\end{array}$ \\
\hline WARM & $\begin{array}{l}F(1.46, \\
21.90)= \\
2.42, p= \\
0.12\end{array}$ & $\begin{array}{l}\mathrm{F}(1,15)= \\
1.20, \mathrm{p}= \\
0.29\end{array}$ & $\begin{array}{l}\mathrm{F}(1,15)= \\
0.00, \mathrm{p}= \\
1.00\end{array}$ & $\begin{array}{l}F(2,28)= \\
0.76, p= \\
0.48\end{array}$ & $\begin{array}{l}F(2,28)= \\
3.13, p= \\
0.06\end{array}$ & $\begin{array}{l}F(1,14)= \\
0.89, p= \\
0.36\end{array}$ & $\begin{array}{l}F(2,28)= \\
0.48, p= \\
0.63\end{array}$ \\
\hline \multirow[t]{2}{*}{ COLD } & $\begin{array}{l}\mathrm{F}(2,30)= \\
1.92, \mathrm{p}= \\
0.16\end{array}$ & $\begin{array}{l}F(1,15)= \\
0.35, p= \\
0.57\end{array}$ & $\begin{array}{l}F(1,15)= \\
0.39, p= \\
0.54\end{array}$ & $\begin{array}{l}F(1.81, \\
25.39)= \\
0.10, p= \\
0.89\end{array}$ & $\begin{array}{l}F(1.78, \\
24.90)= \\
0.81, p= \\
0.44\end{array}$ & $\begin{array}{l}F(1,14)= \\
0.27, p= \\
0.61\end{array}$ & $\begin{array}{l}F(1.81, \\
25.39)= \\
3.48, p= \\
0.05\end{array}$ \\
\hline & $\begin{array}{l}\text { LEN* } \\
\text { Gender }\end{array}$ & $\begin{array}{l}\text { EXT* } \\
\text { Gender }\end{array}$ & $\begin{array}{l}\text { ROC** } \\
\text { Gender }\end{array}$ & $\begin{array}{l}\text { LEN* } \\
\text { EXT* } \\
\text { Gender }\end{array}$ & $\begin{array}{l}\text { LEN* } \\
\text { ROC* } \\
\text { Gender }\end{array}$ & $\begin{array}{l}\text { EXT* } \\
\text { ROC* } \\
\text { Gender }\end{array}$ & $\begin{array}{l}\text { LEN* } \\
\text { EXT* } \\
\text { ROC* } \\
\text { Gender }\end{array}$ \\
\hline WARM & $\begin{array}{l}F(1.3,17.7) \\
=3.06, p= \\
0.09\end{array}$ & $\begin{array}{l}F(1,14)= \\
0.16, p= \\
0.69\end{array}$ & $\begin{array}{l}F(1,14)= \\
0.26, p= \\
0.62\end{array}$ & $\begin{array}{l}F(2,28)= \\
0.36, p= \\
0.70\end{array}$ & $\begin{array}{l}F(2,28)= \\
0.44, p= \\
0.65\end{array}$ & $\begin{array}{l}F(1,14)= \\
0.47, p= \\
0.50\end{array}$ & $\begin{array}{l}F(2,28)= \\
0.98, p= \\
0.39\end{array}$ \\
\hline COLD & $\begin{array}{l}F(1.89, \\
26.50)= \\
2.79, p= \\
0.08\end{array}$ & $\begin{array}{l}F(1,14)= \\
0.04, p= \\
0.85\end{array}$ & $\begin{array}{l}F(1,14)= \\
3.35, p= \\
0.09\end{array}$ & $\begin{array}{l}F(1.81, \\
25.39)= \\
1.36, p= \\
0.27\end{array}$ & $\begin{array}{l}F(1.78, \\
24.90)= \\
0.81, p= \\
0.44\end{array}$ & $\begin{array}{l}F(1,14)= \\
0.64, p= \\
0.44\end{array}$ & $\begin{array}{l}\mathrm{F}(1.81, \\
25.39)= \\
1.25 \\
\mathrm{p}=0.30\end{array}$ \\
\hline
\end{tabular}

Figure 7. Percentage of false positive recognitions ordered by parameters

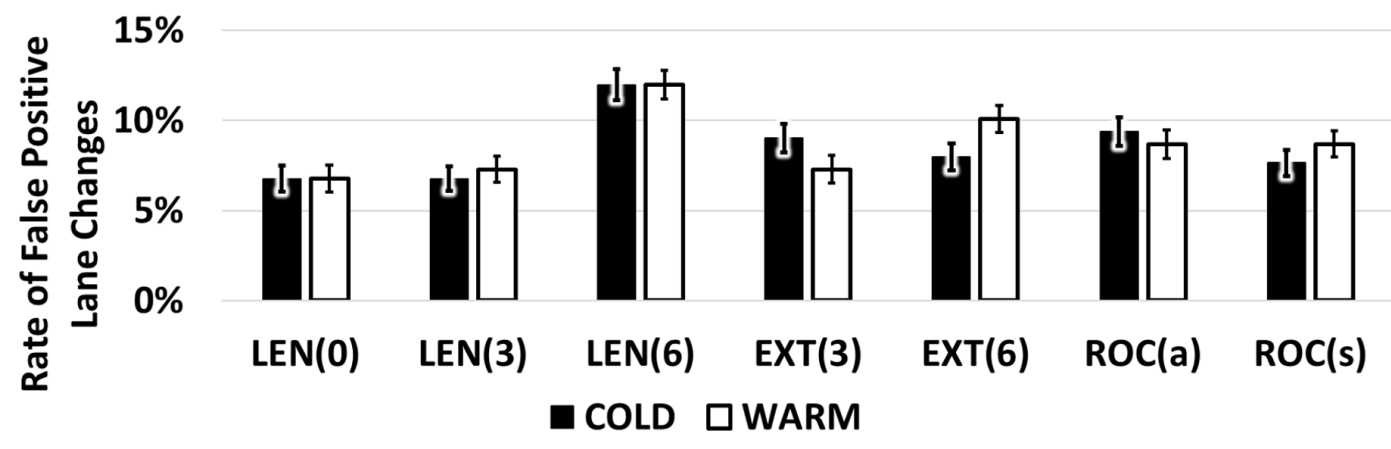

Figure 8. Percentage of false positive recognitions for each stimulus

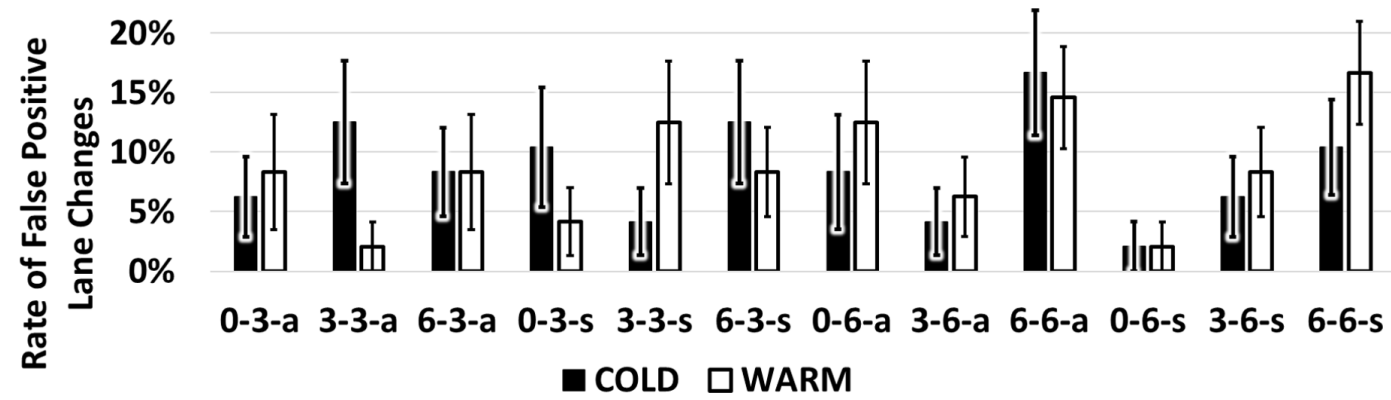


Table 5. Test results for the ANOVA tests for the recognition

\begin{tabular}{|c|c|c|c|c|c|c|c|}
\hline & LEN & EXT & ROC & LEN*EXT & LEN*ROC & EXT*ROC & $\begin{array}{c}\text { LEN* } \\
\text { EXT*ROC }\end{array}$ \\
\hline WARM & $\begin{array}{l}\mathrm{F}(1.41, \\
21.20)= \\
10.75, \mathbf{p}= \\
\mathbf{0 . 0 0 2}\end{array}$ & $\begin{array}{l}F(1,15)= \\
23.13, \mathbf{p}< \\
\mathbf{0 . 0 0 1}\end{array}$ & $\begin{array}{l}F(1,15)= \\
2.36, p= \\
0.15\end{array}$ & $\begin{array}{l}F(2,28)= \\
7.96, \mathbf{p}= \\
\mathbf{0 . 0 0 2}\end{array}$ & $\begin{array}{l}\mathrm{F}(2,28)= \\
1.08, \mathrm{p}= \\
0.35\end{array}$ & $\begin{array}{l}F(1,14)= \\
0.56, p= \\
0.47\end{array}$ & $\begin{array}{l}F(2,28)= \\
1.49, p= \\
0.24\end{array}$ \\
\hline \multirow[t]{2}{*}{ COLD } & $\begin{array}{l}\mathrm{F}(2,30)= \\
1.34, \mathrm{p}= \\
0.28\end{array}$ & $\begin{array}{l}F(1,15)= \\
8.37, \mathbf{p}= \\
\mathbf{0 . 0 1}\end{array}$ & $\begin{array}{l}\mathrm{F}(1,15)= \\
1.47, \mathrm{p}= \\
0.24\end{array}$ & $\begin{array}{l}\mathrm{F}(2,28)= \\
1.27, \mathrm{p}= \\
0.30\end{array}$ & $\begin{array}{l}\mathrm{F}(2,28)= \\
1.38, \mathrm{p}= \\
0.27\end{array}$ & $\begin{array}{l}F(1,14)= \\
0.80, p= \\
0.39\end{array}$ & $\begin{array}{l}\mathrm{F}(2,28)= \\
1.21, \mathrm{p}= \\
0.31\end{array}$ \\
\hline & $\begin{array}{l}\text { LEN* } \\
\text { Gender }\end{array}$ & $\begin{array}{l}\text { EXT* } \\
\text { Gender }\end{array}$ & $\begin{array}{l}\text { ROC* } \\
\text { Gender }\end{array}$ & $\begin{array}{l}\text { LEN* } \\
\text { EXT* } \\
\text { Gender }\end{array}$ & $\begin{array}{l}\text { LEN* } \\
\text { ROC* } \\
\text { Gender }\end{array}$ & $\begin{array}{l}\text { EXT* } \\
\text { ROC* } \\
\text { Gender }\end{array}$ & $\begin{array}{l}\text { LEN* } \\
\text { EXT* } \\
\text { ROC* } \\
\text { Gender }\end{array}$ \\
\hline WARM & $\begin{array}{l}F(1.43, \\
20.01)= \\
2.89, p= \\
0.09\end{array}$ & $\begin{array}{l}F(1,14)= \\
0.04, p= \\
0.84\end{array}$ & $\begin{array}{l}\mathrm{F}(1,14)= \\
0.09, \mathrm{p}= \\
0.77\end{array}$ & $\begin{array}{l}\mathrm{F}(2,28)= \\
2.33, \mathrm{p}= \\
0.12\end{array}$ & $\begin{array}{l}F(2,28)= \\
0.44, p= \\
0.65\end{array}$ & $\begin{array}{l}\mathrm{F}(1,14)< \\
0.001, \mathrm{p}= \\
1.00\end{array}$ & $\begin{array}{l}F(2,28)= \\
0.51, p= \\
0.61\end{array}$ \\
\hline COLD & $\begin{array}{l}F(2,28)= \\
0.15, p= \\
0.86\end{array}$ & $\begin{array}{l}\mathrm{F}(1,14)= \\
0.05, \mathrm{p}= \\
0.83\end{array}$ & $\begin{array}{l}\mathrm{F}(1,14)= \\
0.06, \mathrm{p}= \\
0.81\end{array}$ & $\begin{array}{l}F(2,28)= \\
0.17, p= \\
0.84\end{array}$ & $\begin{array}{l}F(2,28)= \\
0.27, p= \\
0.77\end{array}$ & $\begin{array}{l}F(1,14)= \\
0.09, p= \\
0.77\end{array}$ & $\begin{array}{l}F(2,28)= \\
0.94, p= \\
0.40\end{array}$ \\
\hline
\end{tabular}

\section{Recognition}

Repeated measures ANOVAs were employed to evaluate the recognition for warm and cold stimuli for all parameters. Test results can be seen in Table 5. Sphericity was violated for LEN for the warm stimuli and the interaction of all three parameters for cold stimuli and was corrected with Greenhouse-Geisser. Figure 9 and 10 show the recognition rates for the parameters and for each stimulus, respectively.

For the cold stimuli, the repeated measures ANOVA found a significant difference for EXT (see Table 5 COLD). The investigations of interactions showed no significant results, yielding a clear main effect. The higher extent of $6^{\circ} \mathrm{C}$ resulted in a better recognition rate $(272$ out of 288$)$ than $3^{\circ} \mathrm{C}(246)$.

LEN and EXT showed significant differences for warm stimuli (see Table 5 WARM), but there was an interaction between the two parameters. Post hoc tests for the interaction effect with a Tukey correction showed significant results only for the LEN, EXT combination of 0,3 with all other combinations, see Table 6 . The recognition of 0,3 had a lower recognition than the other combinations, compare Figure 11.

\section{Time to Complete a Lane Change}

The mean time to complete lane change can be seen in Figure 12 for each stimulus. The overall mean time for cold stimuli was 5.11s $(S D=0.45)$, for warm stimuli $5.17 \mathrm{~s}(S D=0.14)$. The times were not normally distributed, and a Wilcoxon test showed no significance for temperature direction on the time to complete lane change $(\mathrm{Z}=1.241 \mathrm{p}=0.22)$.

\section{Discussion}

This experiment was conducted to investigate the impact of stimuli design on the recognition rate and the false positive recognitions at the return to the neutral temperature. The results showed no significant impact of the parameters on false positives. Furthermore, the gender differences observed in the second part of the first experiment could not be observed in this study either. Even though not statistically significant, the extent of temperature change seems to lead to a higher number of lane changes for warm temperatures, while it seems to be the opposite way around for cold temperatures, 
Table 6. Post hoc tests for the interaction LEN*EXT for warm temperatures with Tukey corrections. Degree of freedom for all was 165 , results were averaged over ROC.

\begin{tabular}{|l|l|l|l|l|l|}
\hline \multicolumn{1}{|c|}{ Comparison } & \multicolumn{1}{|c|}{ t-Value } & \multicolumn{1}{c|}{ p-Value } & \multicolumn{1}{c|}{ Comparison } & \multicolumn{1}{c|}{ t-Value } & \multicolumn{1}{c|}{ p-Value } \\
\hline $0,3-3,3$ & 5.63 & $<\mathbf{0 . 0 0 1}$ & $3,3-6,6$ & 1.71 & 0.53 \\
\hline $0,3-6,3$ & 4.65 & $<\mathbf{0 . 0 0 1}$ & $6,3-0,6$ & 2.20 & 0.24 \\
\hline $0,3-0,6$ & 6.85 & $<\mathbf{0 . 0 0 1}$ & $6,3-3,6$ & 2.69 & 0.08 \\
\hline $0,3-3,6$ & 7.34 & $<\mathbf{0 . 0 0 1}$ & $6,3-6,6$ & 2.69 & 0.08 \\
\hline $0,3-6,6$ & 7.34 & $<\mathbf{0 . 0 0 1}$ & $0,6-3,6$ & 0.49 & 1.00 \\
\hline $3,3-6,3$ & 0.98 & 0.92 & $0,6-6,6$ & 0.49 & 1.00 \\
\hline $3,3-0,6$ & 1.22 & 0.83 & $3,6-6,6$ & 0.00 & 1.00 \\
\hline $3,3-3,6$ & 1.71 & 0.53 & & & \\
\hline
\end{tabular}

Figure 9. Recognition rates for the parameters
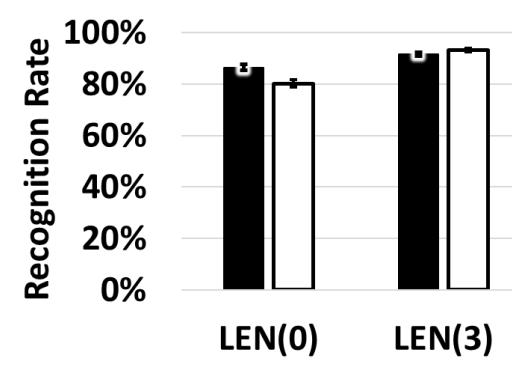

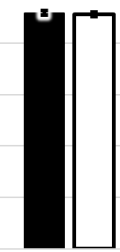

LEN(6)

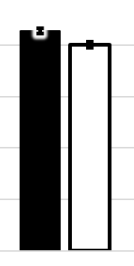

EXT(3)

WARM

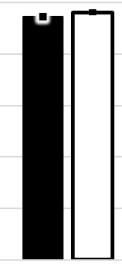

$\operatorname{EXT}(6)$

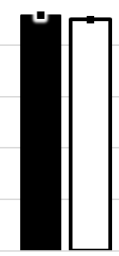

ROC(a)

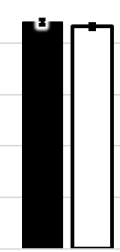

ROC(s)

COLD IWARM

Figure 10. Recognition rates for each stimulus
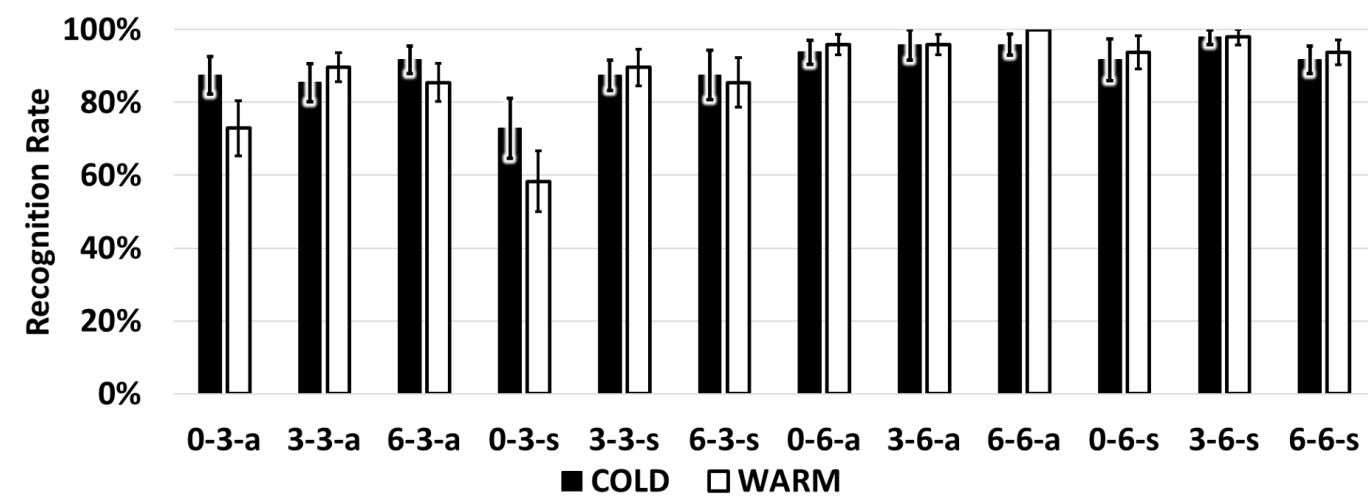

where the lesser extent seems to have elicited more changes back. In the case of cold temperature changes an additional correlation with the rate of change might exist: the slowest rate of change seems to lead to more lane changes. Future studies should observe if the trends become more relevant in a more extensive setup.

The recognition rate of cold stimuli was influenced by the extent of thermal change: bigger changes were recognized better. For warm stimuli, if the temperature after a change of $3^{\circ} \mathrm{C}$ was 


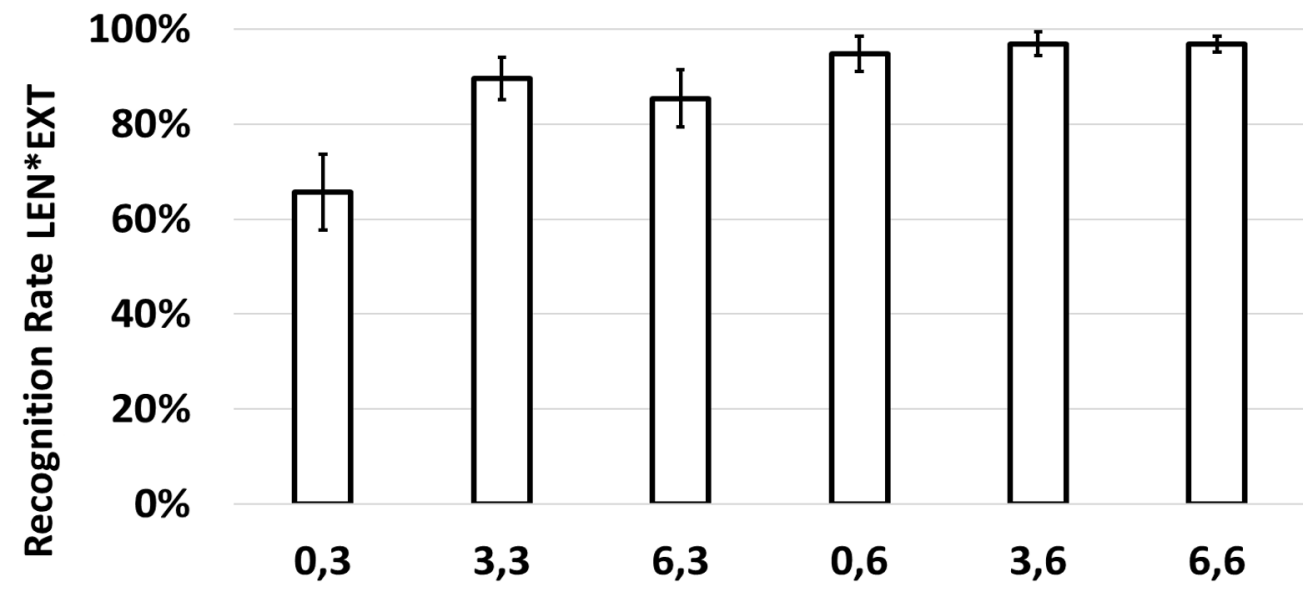

Figure 12. Mean Time to Completed Lane Change for each stimulus

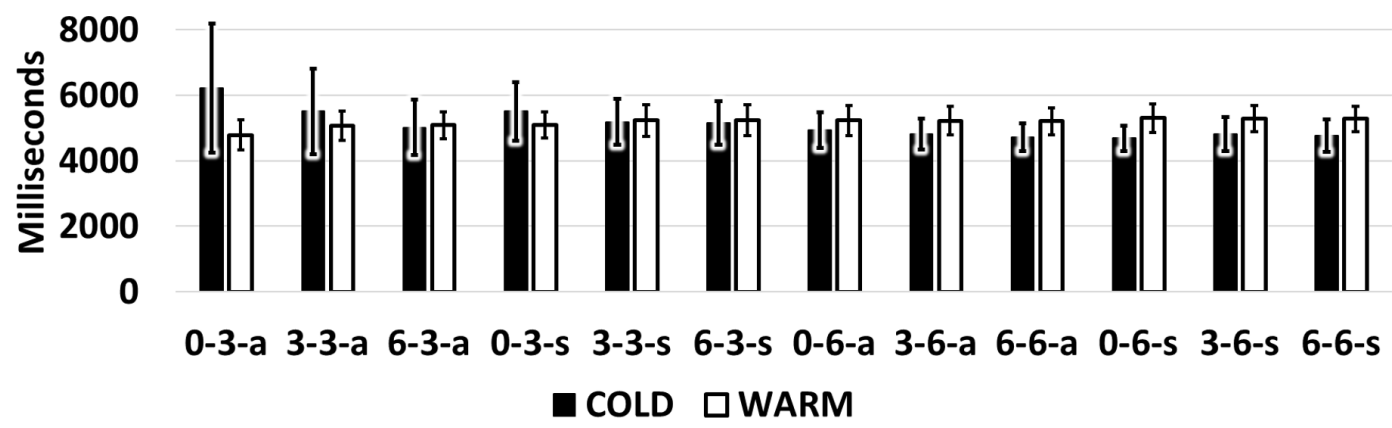

changed back as soon as the destination temperature was reached, the recognition was influenced negatively. However, only one stimulus reached a perfect recognition rate: w-6-6-a. Unfortunately, the number of false positives was one of the highest for this stimulus.

These differences in how the results are affected for the two directions of temperature show that a direct mirroring of stimuli design might not work. Additionally, the choice of stimulus features depends highly on the prioritized result: should the design aim for a high recognition rate or try to minimize false positives?

\section{CONCLUSION AND FUTURE WORK}

These two studies have gathered insights into thermal feedback during driving. Future studies will have to confirm the results, as the sample size was small and limited to right-handed participants. Furthermore, the driving task was restricted by enforcing one-handed driving and providing a constant speed. Nonetheless, these experiments highlight some important features and challenges for thermal interaction during driving.

The comparison of the distraction, measured through lane deviation, between speech and thermal feedback did not show any significant results. The lane changes in the thermal condition took around $5 \mathrm{~s}$ in both experiments, less than $2 \mathrm{~s}$ more than in the audio condition. Overall, speech was rated as more pleasant and less complicated. Especially the male participants in the first experiment seemed to 
experience thermal feedback as more demanding than women, whereas they also rate speech feedback as more disrupting than women. Gender differences in false positive recognitions were only observed in the second part of the first experiment. However, this difference could not be observed in the second experiment. This would suggest that the recognition of thermal feedback is not or only marginally influenced by gender and thermal feedback can be effectively used independent of this aspect. These claims will have to be confirmed in future studies, as the sample size was small in these experiments.

The high rating of audio feedback could be influenced by the familiarity of speech as well as the lack of additional mapping needed in the thermal condition. This will be investigated in future work, along the use of thermal feedback for notifications, as these could benefit from the intrinsic impression of urgency associated with hot temperatures. As the identification of thermal feedback takes time, it could be used for notifications of a less urgent manner, where vibration would be unnecessarily attention grabbing, as for example to notify when fuel is running low, or for foreseeable events, such as turning points in navigation. Some ideas have been provided by participants. The second experiment showed that the stimuli design must be specific and cannot easily be mirrored for warm and cold stimuli. Conveying direction with thermal interaction without additional information does not seem to be feasible. Spatial information, given by the location of the thermal feedback, could aid the situation. A car provides the best possible environment for thermal feedback, as it is well defined, the driver's position is well known as is the in-car temperature. Additional installation of sensors could make thermal feedback even more adjustable. To keep thermal comfort for the drivers, we envision thermal feedback to be adaptable, so drivers can individually set it according to their preference.

\section{ACKNOWLEDGMENT}

This research was supported by an EPSRC iCASE Award with Jaguar Land Rover [grant number EP/P510506/1]. 


\section{REFERENCES}

Alexander, J., Marshall, M. T., \& Subramanian, S. (2011). Adding Haptic Feedback to Mobile TV. In Proceedings of the 2011 Annual Conference Extended Abstracts on Human Factors in Computing Systems - CHI EA '11. doi:10.1145/1979742.1979899

Brewster, S., \& Brown, L. M. (2004). Tactons: structured tactile messages for non-visual information display. In AUIC'04 Proceedings of the Fifth Conference on Australasian User Interface (pp. 15-23). Retrieved from www.dcs.gla.ac.uk/ stephen

Brown, L. M., Brewster, S., \& Purchase, H. C. (2006). Multidimensional Tactons for Non-Visual Information Presentation in Mobile Devices. In Proceedings of the 8th Conference on Human-Computer Interaction with Mobile Devices and Services - MobileHCI 'O6 (pp. 231-238). doi:10.1145/1152215.1152265

Brown, L. M., \& Kaaresoja, T. (2006). Feel Who's Talking: Using Tactons for Mobile Phone Alerts. In CHI '06 Extended Abstracts on Human Factors in Computing Systems - CHI EA '06. doi:<ALIGNMENT.qj ></ ALIGNMENT > 10.1145/1125451.1125577

Di Campli San Vito, P., Brewster, S., Pollick, F., White, S., Skrypchuk, L., \& Mouzakitis, A. (2018). Investigation of Thermal Stimuli for Lane Changes. In Proceedings of the 10th International Conference on Automotive User Interfaces and Interactive Vehicular Applications (pp. 43-52). doi:10.1145/3239060.3239062

Geitner, C., Birrell, S., Skrypchuk, L., Krehl, C., Mouzakitis, A., \& Jennings, P. (2015). Good Vibrations Driving with a Haptic Pedal. In Adjunct Proceedings of the 7th International Conference on Automotive User Interfaces and Interactive Vehicular Applications - AutomotiveUI '15 (pp. 100-105). doi:<ALIGNMENT.qj ></ ALIGNMENT>10.1145/2809730.2809742

Hart, S. G., \& Staveland, L. E. (1988). Development of NASA-TLX (Task Load Index): Results of empirical and theoretical research. Advances in Psychology, 52, 139-183.

Karjalainen, S. (2012). Thermal comfort and gender: A literature review. Indoor Air, 22(2), 96-109. doi:10.1111/ j.1600-0668.2011.00747.x PMID:21955322

Kern, D., Marshall, P., Hornecker, E., Rogers, Y., \& Schmidt, A. (2009). Enhancing navigation information with tactile output embedded into the steering wheel. In International Conference on Pervasive Computing (pp. 42-58). Springer. doi:10.1007/978-3-642-01516-8_5

Klauer, S. G., Dingus, T.A., Neale, V. L., Sudweeks, J. D., \& Ramsey, D. J. (2006). The Impact of Driver Inattention On Near Crash/Crash Risk: An Analysis Using the 100-Car Naturalistic Driving Study Data. NHTSA.

Lee, W., \& Lim, Y. (2010). Thermo-Message: Exploring the Potential of Heat as a Modality of Peripheral Expression. In Proceedings of the 28th of the International Conference Extended Abstracts on Human Factors in Computing Systems - CHI EA '10. doi:10.1145/1753846.1754131

Medeiros-Ward, N., Cooper, J. M., Doxon, A. J., Strayer, D. L., \& Provancher, W. R. (2010). Bypassing the Bottleneck: The Advantage of Fingertip Shear Feedback for Navigational Cues. In Proceedings of the Human Factors and Ergonomics Society (pp. 2043-2047).

Pielot, M., Poppinga, B., \& Boll, S. (2010). PocketNavigator: Vibro-Tactile Waypoint Navigation for Everyday Mobile Devices Martin. In Proceedings of the 12th International Conference on Human Computer Interaction with Mobile Devices and Services - MobileHCI '10. doi:10.1145/1851600.1851696

Salminen, K., Surakka, V., Raisamo, J., Lylykangas, J., Pystynen, J., \& Raisamo, R., ... Ahmaniemi, T. (2011). Emotional responses to thermal stimuli. In Proceedings of the 13th International Conference on Multimodal Interfaces - ICMI'11. doi:10.1145/2070481.2070513

Suzuki, K., \& Jansson, H. (2003). An analysis of driver's steering behaviour during auditory or haptic warnings for the designing of lane departure warning system. JSAE Review, 24(1), 65-70. doi:10.1016/S0389-4304(02)00247-3

Tewell, J., Bird, J., \& Buchanan, G. R. (2017). Heat-Nav: Using Temperature Changes as Navigational Cues. In Proceedings of the 2017 CHI Conference on Human Factors in Computing Systems - CHI '17 (pp. 1131-1135). doi:10.1145/3025453.3025965 
Van Erp, J. B. F., \& Van Veen, H. A. H. C. (2004). Vibrotactile in-vehicle navigation system. Transportation Research Part F: Traffic Psychology and Behaviour, 7(4-5), 247-256. doi:10.1016/j.trf.2004.09.003

Wettach, R., Behrens, C., Danielsson, A., \& Ness, T. (2007). A thermal information display for mobile applications. In Proceedings of the 9th International Conference on Human Computer Interaction with Mobile Devices and Services - MobileHCI '07 (pp. 182-185). doi:10.1145/1377999.1378004

Wilson, G., Brewster, S., Halvey, M., \& Hughes, S. (2013). Thermal feedback identification in a mobile environment. In International Workshop on Haptic and Audio Interaction Design (pp. 10-19). Springer. doi:10.1007/978-3-642-41068-0_2

Wilson, G., Davidson, G., \& Brewster, S. (2015). In the Heat of the Moment: Subjective Interpretations of Thermal Feedback During Interaction. In Proceedings of the ACM CHI'15 Conference on Human Factors in Computing Systems (pp. 18-23). doi:10.1145/2702123.2702167

Wilson, G., Dobrev, D., \& Brewster, S. (2017). Hot Under the Collar: Mapping Thermal Feedback to Dimensional Models of Emotion. In Proceedings of the 2017 ACM Workshop on Interacting with Smart Objects - SmartObject '17 (pp. 31-36). doi:<ALIGNMENT.qj></ALIGNMENT>10.1145/3038450.3038454

Wilson, G., Halvey, M., Brewster, S., \& Hughes, S. A. (2011). Some Like it Hot? Thermal Feedback for Mobile Devices. In Proceedings of the 2011 Annual Conference on Human Factors in Computing Systems - CHI '11. doi:10.1145/1978942.1979316 
Patrizia Di Campli San Vito is a current third-year PhD student at the School of Computing Science of the University of Glasgow, where she is co-funded by Jaguar Land Rover. Her research focuses on the Investigation of Thermal Feedback for In-Car Applications. Patrizia obtained BSc and MSc degrees in Media Informatics from the University of UIm. Before studying Computing Science, she learnt to be a Commercial Correspondent in English with focus on Engineering and Second Language Italian at the School of Languages in Landshut.

Stephen Brewster is Professor of $\mathrm{HCl}$ at the University of Glasgow. He leads the research of the multimodal interaction group (MIG) within the Glasgow Interactive Systems (GIST) Section. He obtained his degree in Computer Science at the University of Herfordshire and did his PhD after a period in industry in the Human-Computer Interaction Group at the University of York. He then worked as a research fellow for the European Union as part of the European Research Consortium for Informatics and Mathematics (ERCIM) and was employed by VTT Information Technology in Helsinki and SINTEF DELAB in Trondheim. Since 1995 Professor Brewster is part of the School of Computing Science in Glasgow. He has held an EPSRC Advanced Research Fellowship investigating the use of haptic feedback for mobile devices and is a member of the ACM SIGCHI Academy, a Fellow of the Royal Society of Edinburgh and an ACM Distinguished Speaker.

Frank Pollick is a Professor of Psychology at the University of Glasgow. He is interested in a variety of topics including the perception of human movement and the cognitive and neural processes that underlie our abilities to understand the actions of others. He is also interested in applying psychological methods to the study of how humans interact with technology. Current research includes brain imaging and how individual differences involving autism and skill expertise are expressed in the brain circuits for action understanding and multisensory perception. He obtained BS degrees in physics and biology from MIT in 1982, an MSc in Biomedical Engineering from Case Western Reserve University in 1984 and a PhD in Cognitive Sciences from The University of California, Irvine in 1991. Following this he was an invited researcher at the ATR Human Information Processing Research Labs in Kyoto, Japan from 1991-97. Since then he has been working in the School of Psychology at the University of Glasgow.

Stuart White received his BEng in Product Design Engineering from the University of Strathclyde Glasgow. On completion of his degree, he worked in Jaguar Land Rover's Human Machine Interface Research department where he led both visual and interaction design of future interface concepts in the team. He and his colleagues filed many technology patents - of which several have been produced and are featured brands' flagship models. During this term, White was the industrial partner project supervisor of this research into thermal feedback for in-car applications. He has since transferred to the mainstream creative Design team in Jaguar Land Rover where he specialises in the design of Graphical User Interfaces from concept to production systems - most recently leading the activity of developing an innovative vision for the company's future interface strategy.

Lee Skrypchuk completed a bachelor's degree in Electronics \& Computing at Nottingham Trent University followed by a Master's degree is Display Technology, Systems \& Applications at Dundee University. He then joined Alpine Electronics in 2003 working on the development of automotive touchscreen interfaces. In 2007 Lee left Alpine and joined Jaguar Land Rover Research working on Human Machine Interface systems, working on a number of technology delivery projects including Dual View Display, Head Up Display, Gesture, Blade Interface system, Haptic Interface Technology and introduced optical performance modelling (SPEOS) to the business. In 2011 he was promoted to position of Human Machine Interface Technical Specialist where his focus is on researching future interface technologies. This covers all technical aspects of interface technologies such as engineering, human factors and psychological aspects. He is currently studying for a PhD in engineering at the University of Cambridge.

Alex Mouzakitis is the head of the Electrical, Electronics and Software Engineering Research Department at Jaguar Land Rover. Dr Mouzakitis has over 15 years of technological and managerial experience especially in the area of automotive embedded systems. In his current role is responsible for leading a multidisciplinary research and technology department dedicated to deliver a portfolio of advanced research projects in the areas of human-machine interface, digital transformation, self-learning vehicle, machine learning \& big data analytics, smart/connected systems and on-board/off board data platforms. DrMouzakitis is a Chartered Engineer and a Fellow of the IET and InstMC engineering institutions. Dr Mouzakitis holds a BSc (Hons) in Integrated Manufacturing Technology and a $\mathrm{PhD}$ in Machine Learning and Artificial Intelligence for Autonomous Vehicles from the University of Wales, an MSc in Systems and Control from Coventry University and an EngD in Automotive Embedded Software Development from the University of Warwick. 